\title{
An Effort-Reward Imbalance Model to Study Engagement and Burnout: A Pilot Study
}

\author{
Jung Eun Hwang ${ }^{1}$, Na Jin Kim², Nani Kwon ${ }^{2} \&$ Su Young Kim ${ }^{1,2}$ \\ ${ }^{1}$ Department of Pathology, College of Medicine, The Catholic University of Korea, Seoul, Republic of Korea \\ ${ }^{2}$ Master Center for Medical Education Support, College of Medicine, The Catholic University of Korea, Seoul, \\ Republic of Korea \\ Correspondence: Su Young Kim, Department of Pathology and Master Center for Medical Education Support, \\ College of Medicine, The Catholic University of Korea, 222 Banpo-daero, Seocho-gu, Seoul 06591, Republic of \\ Korea. Tel: 82-2-2258-7315. E-mail: suyoung.dr@gmail.com
}

Received: April 11, 2019

Accepted: April 29, 2019

Online Published: May 16, 2019

doi:10.20849/jed.v3i2.542

URL: https://doi.org/10.20849/jed.v3i2.542

\begin{abstract}
Introduction: Medical students are motivated to engage actively in their studies. Yet at least $50 \%$ of medical students suffer from academic burnout. Using a social environmental perspective, this pilot study tested six hypotheses to account for medical student engagement and burnout via an effort-reward imbalance (ERI) model.

Methods: This study measured ERI, over-commitment, engagement, burnout, negative affect, demographic variables, and test results during 2017. Seventy-nine medical students at a college of medicine in Seoul, Republic of Korea completed the online questionnaires (response rate: 20.73\%). We used hierarchical regression analyses to examine the effects of ERI ratio, over-commitment, and the interaction between ERI ratio and over-commitment on engagement and burnout after adjusting for demographic variables and negative affect.
\end{abstract}

Results: The ERI ratio was negatively related to engagement $(p<0.05)$, but over-commitment was positively related to engagement $(p<0.05)$. For burnout, affiliation, age, and negative affect were significant predictors. The ERI ratio was positively associated with burnout $(p<0.05)$. When we performed regression analyses on three sub-dimensions of engagement and burnout, the factors that affected each sub-dimension were different.

Discussion: This pilot study revealed that the ERI ratio in school settings is a common factor for explaining the engagement and burnout of medical students. In addition, over-commitment significantly accounted for engagement, but it did not significantly account for burnout. These results for over-commitment may be explained by the unique characteristics of medical students.

Keywords: effort-reward imbalance model, engagement, burnout, undergraduate medical education

\section{Introduction}

Medical students are likely to engage actively in their studies because they are highly motivated to enter medical school, and because they are known to have high intrinsic and/or extrinsic academic motivation (Kusurkar, Croiset, Galindo-Garré, \& Ten Cate, 2013; Kusurkar, Ten Cate, van Asperen, \& Croiset, 2011). At the same time, they are at increased risk of burnout due to a heavy study and clinical practice load (Lee \& Lee, 2013). It has been reported that at least $50 \%$ of medical students suffer from burnout at some point during their studies (Chunming, Harrison, MacIntyre, Travaglia, \& Balasooriya, 2017). This situation shows the need for investigation into factors that enhance the engagement or cause burnout of medical students.

Engagement is defined as a student having a positive and fulfilling experience with his/her studies (Schaufeli, Martinez, Pinto, Salanova, \& Baker, 2002a; Schaufeli, Salanova, Gonzalez-roma, \& Bakker, 2002). According to these researchers, engagement consists of vigor, dedication, and absorption. Vigorous students are energetic and mentally resilient while studying, are willing to study hard, and persist when faced with difficulties. Dedicated students recognize the meaning of their studies, feel enthusiasm and pride, and are inspired. Students absorbed in their studies entirely concentrate on their jobs, perceive time to pass quickly, and have difficulty detaching from their studies. In contrast, academic burnout is characterized by emotional exhaustion, cynicism, and inefficacy (Schaufeli et al., 2002a; 2002b). Emotional exhaustion refers to depletion of emotional resources due to academic burdens. Cynicism is characterized by an indifferent or callous attitude toward study. Lastly, inefficacy 
is a tendency to perceive academic achievement and abilities negatively. Engagement and burnout are sometimes seen as related constructs on opposite sides of the same continuum. However, this is not necessarily true. In research on the sub-dimensions of engagement and burnout (Demerouti, Mostert, \& Bakker, 2010), it was found that dedication and cynicism were opposing concepts on the same continuum in terms of identifying jobs. But vigor differed from emotional exhaustion, since vigor refers to a willingness to expend effort and energy besides energetic state when at work. In addition, some medical students are emotionally exhausted and depersonalized, but maintain moderate levels of engagement (Gómez et al., 2015). Thus, it can be argued that engagement and burnout are independent constructs.

Recent research suggests that burnout needs to be understood from a social environmental perspective (Chunming et al., 2017; Maslach \& Leiter, 2017). It was emphasized that a person in health care is burned out when their job is not well-matched to them in six areas, and that a better job-person fit predicts engagement (Maslach \& Leiter, 2017). They also recommended that medical education institutions deal with burnout from this perspective. One socio-environmental view, the effort-reward imbalance (ERI) model, explains chronic work stress as a ratio of effort to reward and as over-commitment (OC) (Siegrist, 1996). Effort, a component of the model, represents the burden of the workload. Reward consists of income, career prospects, esteem, and job stability. OC is an individual's inherent style of coping with demanding situations. Over-committed persons are described as having a high need for control and approval whereby they do not withdraw from their jobs (Siegrist, 1996; Siegrist et al., 2004; Siegrist, Wege, Puhlhofer, \& Wahrendorf, 2009). The ERI model focuses on reciprocity of effort and reward. A high ERI ratio refers to less reward than effort. Conversely, a low ERI ratio represents a situation where effort is reciprocally rewarded, or the reward is more than the effort. Siegrist et al. $(1996,2004)$ reported that emotional pain, arousal of the autonomic nervous system, and other reactions to stress occur in high-ERI-ratio conditions, suggesting that over-committed persons are at risk of poor health. This adverse effect of a high ERI ratio on health is aggravated by OC (Siegrist, 1996; Siegrist et al., 2004). According to one review of the relationship between ERI and health (van Vegchel, de Jonge, Bosma, \& Schaufeli, 2005), the detrimental effects of a high ERI ratio on health are consistently reported, whereas the relationship between OC and health is inconsistent. Moreover, researchers (van Vegchel et al., 2005) have implied that the interaction between the ERI ratio and OC needs to be examined in diverse populations.

The ERI model has been applied to account for the academic burnout of adolescents (Kim, Kim, \& Lee, 2017; Lee, Puig, \& Lee, 2012). When students do not (or are not expected to) receive good grades, approval, and appropriate help relative to the time and energy spent on study, they report burnout. Likewise, stressful environments are generally known to affect college students' health, grades, and career development (Wege, $\mathrm{Li}$, Muth, Angerer, \& Siegrist, 2017). Until now, the ERI model has not been applied to explain the burnout of medical students, who are characterized to have high academic motivation (Kusurkar et al., 2013; Kusurkar et al., 2011) and high self-evaluation standards (Enns, Cox, Sareen, \& Freeman, 2001).

In occupational settings, the ERI model accounts for negative indicators and positive indicators (Feldt et al., 2013; Feuerhahn, Kühnel, \& Kudielka, 2012; Kinnunen, Feldt, \& Makikangas, 2008; Wang, Liu, Zou, Hao, \& $\mathrm{Wu}, 2017)$. To our knowledge, it has not been established whether the ERI model relates to positive indicators in school contexts. Academic engagement can be a positive indicator of a student's sense of accomplishment and positive attitude toward his/her studies. Engagement in colleges (including medical schools) is predictive of academic achievement (Casuso-Holgado et al., 2013; Gómez et al., 2015; Salanova, Schaufeli, Martínez, \& Breso, 2009). This study attempts to explain the engagement of medical students using the ERI model.

\subsection{Literature Review and Hypotheses}

\subsubsection{ERI and Engagement}

To test the effects of ERI ratio, OC, and the interaction between ERI ratio and OC on engagement and burnout in a group of medical students, six hypotheses were developed. First, we hypothesized that a high ERI ratio would be negatively related to the engagement of medical students. A negative correlation between ERI ratio and vigor/dedication was noted in a study of managers (Kinnunen et al., 2008). A recent investigation of nurses (Wang et al., 2017) also found that quantitative workload had a negative impact on vigor, dedication, and absorption in workplaces, but reward had a positive impact on these three sub-dimensions of engagement. In another study, ERI ratio was found to significantly decrease job performance (Feuerhahn et al., 2012). The authors explained that motives for performance decreased when employees had lower gains than costs. For college students, it has been reported that academic motivation has an impact on academic engagement (Choo \& Sohn, 2012). Thus, we assumed that academic effort with few rewards would decrease medical students' engagement by reducing their willingness to study. 
Our second hypothesis was that OC would have positive relationship with medical students' engagement. In the ERI model, OC is a predictor of negative health indices (Siegrist et al., 2004). However, in a sample of highly educated participants, OC positively influenced engagement (Kinnunen et al., 2008; Wang et al., 2017). Specifically, OC was found to predict absorption in a sample of managers (Kinnunen et al., 2008). In a study of nurses (Wang et al., 2017), OC significantly predicted increase in vigor, dedication, and absorption. Considering that OC is higher in highly educated adults (Siegrist et al., 2004), it is possible that medical students desiring to gain respect and expertise are actively engaged in their studies.

Our third hypothesis was that, even with a high ERI ratio, engagement would not decrease sharply if OC was high. Results from testing these interactions have been mixed in occupational settings (Feldt et al., 2013; Feuerhahn et al., 2012; Kinnunen et al., 2008). In a sample of employees at a manufacturing company (Feuerhahn et al., 2012), OC reinforced the adverse effects of ERI ratio on job performance. Authors interpreted this result by suggesting that although over-committed employees had a strong desire for approval, they might withdraw from their work under unfavorable conditions. When both ERI ratio and OC were high in a study of managers (Kinnunen et al., 2008), dedication decreased sharply but absorption decreased slightly. A longitudinal study (Feldt et al., 2013) reported that over-committed managers in high-ERI ratio conditions showed similar levels of work engagement to managers in low-ERI ratio conditions (who were less over-committed). Absorption conceptually overlaps with $\mathrm{OC}$ in that both concepts are characterized by difficulties detaching from work (Kinnunen et al., 2008; Schaufeli et al., 2002b). It is known that medical students have high standards for themselves and strong academic motivation (Enns et al., 2001; Kusurkar et al., 2013). It can be assumed that over-committed medical students will continue to engage in their studies, even when they are not sufficiently rewarded for their academic efforts.

Our hypotheses about the ERI model and engagement are summarized as follows:

Hypothesis 1. The ERI ratio will be negatively associated with engagement.

Hypothesis 2. OC will be positively associated with engagement.

Hypothesis 3. If both the ERI ratio and OC are high, engagement will be sustained.

\subsubsection{ERI and Burnout}

Our fourth hypothesis was that the ERI ratio would be positively related to medical students' burnout. Previous studies on the relationship between ERI ratio and academic burnout (Kim et al., 2017; Lee et al., 2012) have targeted adolescents. The ERI ratio of elementary, middle, and high school students was found to affect emotional exhaustion, cynicism, inefficacy, and antipathy toward study (Lee et al., 2012). A longitudinal study (Kim et al., 2017) showed a significant association between rate of change in the ERI ratio and rate of change in burnout among middle school students. In a recent study of medical students (Hahn, Kropp, Kirschstein, Rucker, \& Muller-Hilke, 2017), the ERI ratio had positive correlation with test anxiety and depression. Given that depression in medical students is closely related to burnout (Kroska, Calarge, O'Hara, Deumic, \& Dindo, 2017), we assumed that the ERI ratio would have positive association with the burnout of medical students.

Our fifth hypothesis was that $\mathrm{OC}$ would be positively related to the burnout of medical students. Although the relationship between OC and burnout has not been verified in academic settings, it was reported that middle school student OC was associated with somatic pain and poor health (Laftman, Modin, Ostberg, Hoven, \& Plenty, 2014). In a sample of medical students, OC was positively correlated with trait anxiety (Hahn et al., 2017). Studies in occupational settings have shown that OC significantly increases work burnout (Lau, 2008; Preckel, Meinel, Kudielka, Haug, \& Fischer, 2007). In particular, over-committed employees suffer emotional exhaustion and depersonalization (Bakker, Killmer, Siegrist, \& Schaufeli, 2000; Rasmussen et al., 2016). Likewise, medical students who are unable to escape their studies may gradually become physically and emotionally exhausted. This could lead to callous attitudes toward study.

Our final hypothesis was that OC would aggravate the relationship between ERI ratio and burnout. In occupational settings (Bakker et al., 2000; de Jonge, Bosma, Peter, \& Siegrist, 2000; Feuerhahn et al., 2012), the ERI ratio has a greater negative effect on emotional exhaustion when OC is high. The negative impact of ERI ratio on inefficacy is also amplified when OC is high (Bakker et al., 2000). In one study (Lau, 2008), work burnout under high-ERI ratio and high-OC conditions was found to be greater than burnout under other conditions. According to the ERI model (Siegrist, 1996), over-committed persons put more intrinsic effort into their jobs. In the case of medical students, over-committed students are more likely to perceive their reward as low because of the large amount of intrinsic effort invested in their academic work, even in demanding conditions. As a result, over-committed medical students in high-ERI ratio conditions may feel more exhausted 
and incompetent than less over-committed students.

Our hypotheses about the ERI model and burnout are summarized as follows:

Hypothesis 4. The ERI ratio will be positively associated with burnout.

Hypothesis 5. OC will be positively associated with burnout.

Hypothesis 6. Adverse effects of the ERI ratio on burnout will be strengthened by OC.

\section{Methods}

The purpose of this pilot study was to apply an ERI model to engagement and burnout for medical students.

\subsection{Participants}

Participants were medical students of the Catholic University of Korea, College of Medicine in Seoul, Republic of Korea. The College of Medicine runs a four-year basic medical education course provided to students in a college of medicine and in a medical graduate school.

Data were collected from September to December in 2017. When students accessed their learning management system, they found an introduction of our study including informed consent information via a pop-up window. After students voluntarily agreed to participate in the survey, they answered a web-based questionnaire. With the consent of participants, data on academic achievement were obtained from our student administrative database. Thirty days and sixty days later, e-mails requesting participation were sent to students. Seventy-nine medical students completed the questionnaire, which represented a $20.73 \%$ response rate. Table 1 presents a demographic description of the study participants.

The study protocol (MC17QESI0046) was approved by the Institutional Review Board of the Catholic University of Korea, College of Medicine. In accordance with the Declaration of Helsinki and its later amendments, all personal information was anonymized, and the research procedure followed ethical standards.

Table 1. Study participant demographics $(\mathrm{N}=79)$

\begin{tabular}{lcc}
\hline \multicolumn{1}{c}{ Demographic variable } & Mean / Standard deviation & Median / Range \\
\hline Age & $25.97 / 2.62$ & $26 / 20-36$ \\
\hline \multicolumn{2}{l}{ Number } & Percent (\%) \\
\hline Male & & \\
\hline Fender & 40 & 50.63 \\
\hline Affiliation & 39 & 49.37 \\
\hline College of medicine & & 15.2 \\
\hline Medical graduate school & 12 & 84.8 \\
\hline Year in school & 67 & \\
\hline First year & & 16.5 \\
\hline Second year & 13 & 27.8 \\
\hline Third year & 22 & 34.2 \\
\hline Fourth year & 27 & 21.5 \\
\hline
\end{tabular}

\subsection{Measurements}

\subsubsection{Effort-Reward Imbalance}

The instrument used was a short student version of the ERI questionnaire (Wege et al., 2017). Wege et al. (2017) modified a short version of the ERI questionnaire (Siegrist et al., 2009) to apply to a college setting. This short ERI questionnaire designed for students was not repetitively validated in other studies. Therefore, we added three items to our questionnaire that had been omitted from the previous ERI questionnaire (Siegrist et al., 2009). For translation into Korean, we referred to an original ERI questionnaire modified for Korean adolescents (Lee, Lee, \& Lee, 2009). The ERI scale consists of three factors: effort (three items), reward (eight items), and over-commitment (six items). Sample questionnaire items include "I have constant time pressure due to a heavy study load" (effort); "I receive the respect I deserve from my fellow students" (reward); "I am not sure whether I 
can successfully accomplish my university training" (reward); and "Student work rarely lets me go; it is still on my mind when I go to bed" (OC). The questionnaire was scored using a 4-point Likert scale (strongly disagree: 1, disagree: 2 , agree: 3 , strongly agree: 4 ). Internal consistencies for the scale in a sample of medical students were 0.67 (effort), 0.65 (reward), and 0.79 (OC) (Wege et al., 2017).

The ERI ratio for every respondent was computed according to the formula suggested in a previous study (Siegrist et al., 2004). There are two methods of transforming the ERI ratio: the binary method or the continuous variable method. We transformed the ratio logarithmically into a continuous variable so as not to lose information like variance (Siegrist et al., 2004; van Vegchel et al., 2005). Thus, when the ratio of effort and reward was 1, value of the ERI ratio was transformed into zero. A value less than zero indicated a student received a relatively high reward for his or her academic endeavors. Similarly, a value greater than zero meant that a student received a small reward for his or her academic effort (or that a reward corresponding to academic endeavor was not expected). The interaction term of ERI ratio and OC was a product of two variables.

\subsubsection{Engagement}

Engagement was measured by the 17-item Utrecht work engagement scale for students (Schaufeli et al., 2002b). The scale is comprised of three factors: vigor (six items), dedication (five items), and absorption (six items). Sample items include "When I'm studying, I feel mentally strong" (vigor); "I find my studies to be full of meaning and purpose" (dedication); and "When I am studying, I forget everything else around me" (absorption). The instrument was validated for college students in Korea. The three factorial structure was confirmed, and internal consistencies of subscales ranged from 0.77 to 0.82 (Choo \& Sohn, 2012). We used the items from their study. Each item was answered on a 7-point Likert scale from 0 (never) to 6 (always). Higher scores reflected greater engagement.

\subsubsection{Burnout}

Burnout was assessed with the 15-item Maslach Burnout Inventory: Student Survey (Schaufeli et al., 2002a), a reliable tool to measure burnout. When the inventory was validated in a sample of Korean medical students, it demonstrated acceptable reliability (from 0.77 to 0.84 ) and validity (Lee \& Lee, 2013). Burnout is described by three components: emotional exhaustion (five items), professional efficacy (six items), and cynicism (four items). Sample items include "I feel emotionally drained by my studies" (emotional exhaustion); "I can effectively solve the problems that arise in my studies" (professional efficacy); and "I have become less interested in my studies since my enrollment at the university" (cynicism). Six items of professional efficacy were recoded so that high scores on the scale reflected greater inefficacy. The scale was scored using a 7-point Likert scale that matched the engagement scale.

\subsubsection{Academic Achievement}

Student academic performance was assessed by several tests per course. A major tool for evaluating basic medical education at our college of medicine is the computer-based test (CBT), which includes multiple-choice questions (MCQs). Mean scores of these exams taken in 2017 were used to represent students' academic achievement. Because it can be difficult to standardize test results across various testing formats, we used only MCQ results. All the mean scores were converted to a scale of 100 points.

\subsubsection{Negative Affect}

Negative affect as a confounder was measured using positive and negative affect schedule (PANAS) scales (Watson, Clark, \& Tellegen, 1988). The PANAS subscale for negative affect contains 10 items, such as "irritable," "ashamed," and "afraid." It uses a 5-point Likert scale format from 1 (very slightly or not at all) to 5 (extremely). The PANAS scale has been validated for Korean college students and employees, for whom the internal consistency for negative affect was 0.87 (Lee, Kim, \& Lee, 2003). We referred to the items used in this study.

\subsubsection{Demographic Variables}

We obtained demographic information about gender, age, affiliation, and year in school. Affiliation was divided into college of medicine and medical graduate school. Year in school was categorized into four groups (first through fourth). Gender and affiliation were converted into dummy variables (gender: $1=$ female; affiliation: $1=$ college of medicine).

\subsection{Statistical Analyses}

A factor analysis of ERI measure was performed to determine whether effort, reward, and OC were distinct concepts. We examined internal consistencies of scales using Cronbach's alpha. Pearson's correlation coefficients were calculated. We conducted an analysis of variance (ANOVA) for ERI ratio, engagement, and 
burnout according to year in school. The goal was to determine whether student stress varied according to year in school (as described in previous studies) (Jafari, Loghmani, \& Montazeri, 2012; Shankar et al., 2014).

Confirming assumptions for multiple linear regression analysis was preceded. First, data exceeding absolute value 3 in residual scatterplots were removed, and detecting influential observations was based on calculation of Cook's distance. Then, normality of residuals was tested by the Shapiro-Wilk test. Linearity and homoscedasticity of the residuals were examined by checking residual scatter plots. Durbin-Watson statistics were used to confirm autocorrelation of error terms. Lastly, continuous variables were mean-centered to avoid a multi-collinearity problem (Aiken \& West, 1991).

We chose hierarchical multiple regression analysis to investigate the extent to which ERI ratio, OC, and interaction term contributed to outcome variables after adjusting for demographic variables and negative affect. To test how well the ERI model predicted engagement and burnout, hierarchical multiple regression analyses were separately performed using the following procedure: (1) demographic variables and a confounder were included in Step 1 to adjust for their effects; (2) the ERI ratio was entered in Step 2; (3) OC was entered in Step 3 ; and (4) an interaction term was added in Step 4 to examine the interaction effect. The level of significance was set at $p<0.05$. A confirmatory factor analysis (CFA) was carried out using AMOS version 25 software. All other analyses were performed using SPSS version 25 software.

\section{Results}

\subsection{Preliminary Analyses}

The factorial structure of the ERI scale was explored using principal component and varimax rotation. We excluded four items whose commonalities were less than 0.4 . Table 2 presents the factor structure of the remaining 13 items of the ERI scale. The variance explained by the three factors was $58.27 \%$. The second factor was associated with effort. In this study, two items from the OC subscale (I get easily overwhelmed by time pressure as I study and People close to me say I sacrifice too much for my studies) belonged to the effort factor. Because the items are related to the heavy study load of medical students, we decided that they could be included within the effort factor. Reward items were loaded on the first factor, and OC items on the third factor. CFA for the three-factorial structure revealed that the overall fit of the model was achieved (Delta2 IFI $=0.91, \mathrm{CFI}=0.90$, RMSEA $=0.07$ ).

Table 3 shows descriptive statistics for the study variables. Correlations indicated that the ERI ratio was significantly related to engagement $(\mathrm{r}=-0.38, p<0.05)$. Reward was significantly related to engagement $(\mathrm{r}=$ $0.52, p<0.05)$, but effort and OC were not associated with engagement. Burnout was significantly related to the ERI ratio $(\mathrm{r}=0.61, p<0.05)$. Effort, reward, and $\mathrm{OC}$ were also significantly correlated with burnout $(\mathrm{r}=0.33$, -0.66 , and 0.23 respectively, $p<0.05$ ). Academic achievement showed no significant correlation with other variables.

The ANOVA results for the variables according to year in school showed that there was a significant difference in burnout according to year in school $(\mathrm{F}=2.92, p<0.05)$ (Table 4). Burnout in the third year $(49.19)$ was higher than that in the first year (40.00). Additional analyses were conducted to verify which sub-dimensions of burnout significantly varied by year in school. The ANOVA results showed that there was a significant difference in cynicism according to year in school $(\mathrm{F}=3.33, p<0.05)$. Cynicism in the third year $(13.30)$ was higher than that in the first year (9.08). Burnout and cynicism gradually increased from the first to the third year.

Table 2. The factorial structure of the 13-item ERI questionnaire

\begin{tabular}{|c|c|c|c|c|}
\hline \multirow{2}{*}{ Subscale } & \multirow{2}{*}{ Item } & \multicolumn{3}{|c|}{ Factor } \\
\hline & & 1 & 2 & 3 \\
\hline \multirow{4}{*}{ Effort } & I get easily overwhelmed by time pressure as I study. ${ }^{a}$ & & 0.77 & \\
\hline & I have constant time pressure due to a heavy study load. & & 0.71 & \\
\hline & $\begin{array}{l}\text { I have many interruptions and disturbances while } \\
\text { preparing for my exams. }\end{array}$ & & 0.66 & \\
\hline & People close to me say I sacrifice too much for my studies. ${ }^{a}$ & & 0.64 & \\
\hline \multirow[b]{2}{*}{ Reward } & I receive the respect I deserve from my fellow students. & 0.76 & & \\
\hline & $\begin{array}{l}\text { Considering all my efforts and achievement, my job } \\
\text { promotion prospects are adequate. }\end{array}$ & 0.75 & & \\
\hline
\end{tabular}


I am not sure whether I can successfully accomplish my university training. ${ }^{b}$

0.69

Considering all my efforts, I receive the appreciation that

I deserve.

0.69

There is little opportunity that my grades will rise. ${ }^{\mathrm{b}} \quad 0.67$

I receive the respect I deserve from my supervisors 0.65 (teachers).

If I postpone something that was supposed to be done today, I'll have trouble sleeping at night.

Academic work is still on my mind when I go to bed.

0.72

$\mathrm{OC}$

As soon as I get up in the morning, I start thinking about study problems.

\begin{tabular}{crrr}
\hline Variance explained (\%) & 23.70 & 18.20 & 16.37 \\
\hline Cumulative variance (\%) & 23.70 & 41.90 & 58.27 \\
\hline
\end{tabular}

${ }^{\text {a }}$ items from the OC subscale

${ }^{\mathrm{b}}$ reverse-coded items

Table 3. Mean (M), standard deviation (SD), range, reliability ${ }^{\mathrm{a}}$, and correlation between variables

\begin{tabular}{|c|c|c|c|c|c|c|c|c|c|c|c|c|c|}
\hline & & M & SD & Range & 1 & 2 & 3 & 4 & 5 & 6 & 7 & 8 & 9 \\
\hline 1 & ERI & 33.06 & 4.20 & $22 \sim 44$ & $(0.62)$ & & & & & & & & \\
\hline 2 & Effort & 11.47 & 2.20 & $7 \sim 16$ & $0.52^{*}$ & $(0.72)$ & & & & & & & \\
\hline 3 & Reward & 15.61 & 3.22 & $6 \sim 21$ & $0.58^{*}$ & $-0.28^{*}$ & $(0.80)$ & & & & & & \\
\hline 4 & OC & 5.99 & 1.89 & $3 \sim 10$ & $0.62^{*}$ & $0.45^{*}$ & -0.08 & $(0.70)$ & & & & & \\
\hline 5 & ERI ratio & 0.10 & 0.35 & $-0.60 \sim 1.38$ & -0.10 & $0.76^{*}$ & $-0.82^{*}$ & $0.30^{*}$ & 1 & & & & \\
\hline 6 & $\mathrm{E}$ & 57.53 & 13.23 & $25 \sim 96$ & $0.45^{*}$ & -0.09 & $0.52^{*}$ & 0.21 & $-0.38^{*}$ & $(0.91)$ & & & \\
\hline 7 & B & 44.57 & 10.97 & $9 \sim 68$ & $-0.23^{*}$ & $0.33^{*}$ & $-0.66^{*}$ & $0.23^{*}$ & $0.61^{*}$ & $-0.69^{*}$ & $(0.84)$ & & \\
\hline 8 & $\mathrm{NA}$ & 24.85 & 8.81 & $10 \sim 50$ & 0.06 & $0.40^{*}$ & $-0.40^{*}$ & $0.33^{*}$ & $0.46^{*}$ & $-0.26^{*}$ & $0.60^{*}$ & $(0.91)$ & \\
\hline 9 & AA & 76.95 & 6.96 & $55.27 \sim 88.76$ & 0.20 & 0.22 & 0.08 & 0.06 & 0.08 & 0.05 & 0.02 & 0.13 & 1 \\
\hline
\end{tabular}

${ }^{a}$ Reliability estimates (Cronbach's alpha) are in parentheses.

ERI: total score on the ERI scale; E: Engagement; B: Burnout; NA: negative affect; AA: academic achievement

Table 4. ANOVA results for burnout and cynicism according to year in school

\begin{tabular}{|c|c|c|c|c|c|c|}
\hline Dependent variable & $\begin{array}{l}\text { Year in } \\
\text { school }\end{array}$ & Mean & $\begin{array}{c}\text { Degrees of } \\
\text { freedom }\end{array}$ & $\begin{array}{c}\text { Sum } \\
\text { squared }\end{array}$ & $\begin{array}{c}\text { Mean } \\
\text { squared }\end{array}$ & $\mathrm{F}$ \\
\hline \multirow{4}{*}{ Burnout } & 1 & 40.00 & \multirow{4}{*}{3} & \multirow{4}{*}{979.98} & \multirow{4}{*}{326.66} & \multirow{4}{*}{$2.92^{*}$} \\
\hline & 2 & 43.59 & & & & \\
\hline & 3 & 49.19 & & & & \\
\hline & 4 & 42.00 & & & & \\
\hline \multirow{4}{*}{ Cynicism } & 1 & 9.08 & \multirow{4}{*}{3} & \multirow{4}{*}{211.39} & \multirow{4}{*}{70.47} & \multirow{4}{*}{$3.33^{*}$} \\
\hline & 2 & 9.95 & & & & \\
\hline & 3 & 13.30 & & & & \\
\hline & 4 & 11.29 & & & & \\
\hline
\end{tabular}




\subsection{Ability of the ERI Model to Predict Engagement}

After checking a residual scatterplot, two cases were excluded because standardized predicted values exceeded absolute value 3; one case was removed since age was not answered. In the remaining data, maximum value of Cook's distance was 0.16. The Shapiro-Wilk test for residuals showed that the residuals met the normality assumption $(p=0.10)$. Values on the residual scatterplot were relatively evenly scattered around zero. The Durbin-Watson statistic was 1.87 , indicating that there was no autocorrelation of error terms.

The results of a hierarchical regression analysis predicting engagement are presented in Table 5. In Step 1, demographic variables and negative affect did not significantly account for engagement. When the ERI ratio was introduced in Step 2, it explained an additional $6 \%$ of the Step 1 variance $(\Delta \mathrm{F}=5.44, p<0.05)$. In this model, the ERI ratio $(\mathrm{B}=-13.19, p<0.05)$ was significantly related to engagement. In Step 3, OC explained an additional $17 \%$ of the Step 2 variance $(\Delta \mathrm{F}=17.85, p<0.05)$. In this model, $\mathrm{OC}(\mathrm{B}=3.14, p<0.05)$ was significantly associated with engagement. The ERI ratio $(\mathrm{B}=-18.24, p<0.05)$ was still significant. In Step 4 , an interaction term between the ERI ratio and OC did not have significant association with engagement. Thus, hypotheses 1 and 2 were fully supported, but hypothesis 3 was not.

Table 5. Results of hierarchical regression analysis predicting engagement $(\mathrm{N}=76)$

\begin{tabular}{|c|c|c|c|c|c|c|c|c|}
\hline \multirow{2}{*}{ Variable } & \multicolumn{2}{|c|}{ Step 1} & \multicolumn{2}{|c|}{ Step 2} & \multicolumn{2}{|c|}{ Step 3} & \multicolumn{2}{|c|}{ Step 4} \\
\hline & B & $\beta$ & B & $\beta$ & B & $\beta$ & B & $\beta$ \\
\hline Gender (female) & -0.10 & -0.00 & -0.46 & -0.02 & -1.22 & -0.05 & -1.01 & -0.04 \\
\hline Affiliation (college) & 8.18 & 0.23 & 8.53 & 0.24 & 8.17 & 0.23 & 6.51 & 0.19 \\
\hline Year in school & 1.22 & 0.10 & 0.58 & 0.05 & 1.83 & 0.15 & 1.28 & 0.10 \\
\hline Age & 0.89 & 0.18 & 1.17 & 0.24 & 0.73 & 0.15 & 0.75 & 0.16 \\
\hline Negative affect & $-0.37^{*}$ & -0.26 & -0.11 & -0.07 & -0.26 & -0.18 & -0.34 & -0.24 \\
\hline ERI ratio & & & $-13.19^{*}$ & -0.31 & $-18.24^{*}$ & -0.43 & -16.83 & -0.40 \\
\hline $\mathrm{OC}$ & & & & & $3.14^{*}$ & 0.47 & $2.80^{*}$ & 0.42 \\
\hline ERI ratio $\mathrm{x} O C$ & & & & & & & 4.16 & 0.17 \\
\hline $\mathrm{R}^{2}$ & \multicolumn{2}{|c|}{0.13} & \multicolumn{2}{|c|}{0.19} & \multicolumn{2}{|c|}{0.36} & \multicolumn{2}{|c|}{0.38} \\
\hline$\Delta \mathrm{R}^{2}$ & \multicolumn{2}{|c|}{0.13} & \multicolumn{2}{|c|}{0.06} & \multicolumn{2}{|c|}{0.17} & \multicolumn{2}{|c|}{0.02} \\
\hline$\Delta \mathrm{F}$ & \multicolumn{2}{|c|}{2.08} & \multicolumn{2}{|c|}{$5.44^{*}$} & \multicolumn{2}{|c|}{$17.85^{*}$} & \multicolumn{2}{|c|}{2.43} \\
\hline
\end{tabular}

We conducted additional regression analyses by setting three sub-dimensions of engagement (vigor, dedication, and absorption) as outcome variables (Table 6). The ERI ratio and OC had significant relationships with vigor, dedication, and absorption. An interaction term was significantly related to absorption. That is, the absorption of highly over-committed students increased slightly under high-ERI ratio condition. However, less over-committed students reported lower absorption under high-ERI ratio conditions than under low-ERI ratio conditions (Figure 1).

Table 6. Significant predictors of vigor, dedication, and absorption $(\mathrm{N}=76)$

\begin{tabular}{llllllll}
\hline $\begin{array}{l}\text { Outcome } \\
\text { variable }\end{array}$ & Step & $\begin{array}{l}\text { Significant } \\
\text { predictors }\end{array}$ & $\mathrm{B}$ & $\beta$ & $\mathrm{R}^{2}$ & $\Delta \mathrm{R}^{2}$ & $\Delta \mathrm{F}$ \\
\hline Vigor & 1 & $\begin{array}{l}\text { Age } \\
\text { Negative affect }\end{array}$ & $\begin{array}{l}0.50 \\
-0.15\end{array}$ & $\begin{array}{l}0.25 \\
-0.27\end{array}$ & 0.17 & 0.17 & $2.78^{*}$ \\
& 2 & Age & 0.60 & 0.31 & 0.22 & 0.06 & $4.98^{*}$ \\
& & ERI ratio & -4.98 & -0.30 & & & \\
\cline { 2 - 8 } & 3 & ERI ratio & -6.94 & -0.41 & 0.38 & 0.16 & $17.35^{*}$ \\
& & OC & 1.23 & 0.45 & & & \\
\hline Dedication & 1 & Negative affect & -0.21 & -0.38 & 0.18 & 0.18 & $3.12^{*}$ \\
\hline
\end{tabular}




\begin{tabular}{|c|c|c|c|c|c|c|c|}
\hline & 2 & ERI ratio & -4.55 & -0.28 & 0.23 & 0.05 & $4.70^{*}$ \\
\hline & \multirow[t]{3}{*}{3} & Negative affect & -0.15 & -0.27 & 0.28 & 0.05 & $4.26^{*}$ \\
\hline & & ERI ratio & -5.54 & -0.35 & & & \\
\hline & & $\mathrm{OC}$ & 0.62 & 0.24 & & & \\
\hline \multirow[t]{5}{*}{ Absorption } & 3 & ERI ratio & -5.75 & -0.36 & 0.27 & 0.20 & $18.34^{*}$ \\
\hline & & $\mathrm{OC}$ & 1.30 & 0.51 & & & \\
\hline & 4 & ERI ratio & -4.69 & -0.29 & 0.36 & 0.09 & $9.19^{*}$ \\
\hline & & $\mathrm{OC}$ & 1.04 & 0.41 & & & \\
\hline & & ERI ratio $\mathrm{x}$ OC & 3.14 & 0.34 & & & \\
\hline
\end{tabular}

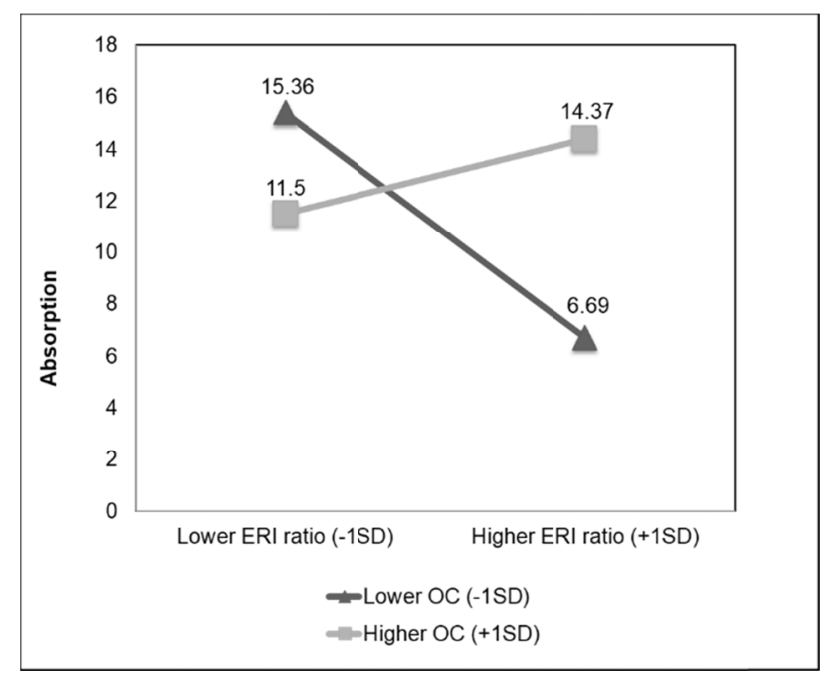

Figure 1. The interaction between ERI ratio and OC on absorption

SD: standard deviation

\subsection{Ability of the ERI Model to Predict Burnout}

There was no case in which values in a residual scatter plot exceeded absolute value 3 . Maximum value of Cook's distance was 0.21 . Shapiro-Wilk test for residuals yielded normality of the residuals $(p=0.39)$. Values on the scatter plot were relatively evenly distributed around zero. The Durbin-Watson statistic was 1.89 , indicating that there was no autocorrelation of error terms.

The results of a hierarchical regression analysis predicting burnout are shown in Table 7. In Step 1, demographic variables and negative affect explained $43 \%$ of the variance in burnout $(\Delta \mathrm{F}=10.71, p<0.05)$. Out of the variables entered in Step 1 , negative affect $(\mathrm{B}=0.70, p<0.05)$ was strongly associated with burnout. Compared to medical graduate students, students in the college of medicine reported lower academic burnout $(\mathrm{B}=-8.02, p$ $<0.05)$. In Step 2, the ERI ratio accounted for an additional $16 \%$ of the Step 1 variance in burnout $(\Delta \mathrm{F}=26.53$, $p<0.05)$. In this model, the ERI ratio was the strongest factor related to burnout $(\mathrm{B}=14.00)$. Affiliation $(\mathrm{B}=$ -7.06), age $(\mathrm{B}=-0.86)$, and negative affect $(\mathrm{B}=0.44)$ were also significant at $p<0.05$. We introduced $\mathrm{OC}$ in Step 3 and the interaction term in Step 4, but F changes in these steps were not significant. That is, OC and the interaction term did not significantly explain burnout after adjustment for demographic variables, negative affect, and ERI ratio. Thus, hypothesis 4 was supported, but hypotheses 5 and 6 were not.

We also performed regression analyses on three sub-dimensions of burnout (emotional exhaustion, inefficacy, and cynicism) (Table 8). The ERI ratio was significantly associated with the three sub-dimensions. OC was positively related to emotional exhaustion, but it was negatively related to inefficacy. 
Table 7. Results of hierarchical regression analysis predicting burnout $(\mathrm{N}=79)$

\begin{tabular}{|c|c|c|c|c|c|c|c|c|}
\hline \multirow{2}{*}{ Variables } & \multicolumn{2}{|c|}{ Step 1} & \multicolumn{2}{|c|}{ Step 2} & \multicolumn{2}{|c|}{ Step 3} & \multicolumn{2}{|c|}{ Step 4} \\
\hline & B & $\beta$ & B & $\beta$ & B & $\beta$ & B & $\beta$ \\
\hline Gender (female) & 2.38 & 0.11 & 2.56 & 0.12 & 3.14 & 0.12 & 2.53 & 0.12 \\
\hline Affiliation (college) & $-8.02^{*}$ & -0.26 & $-7.06^{*}$ & -0.23 & $-7.99^{*}$ & -0.23 & $-6.89^{*}$ & -0.23 \\
\hline Year in school & -0.77 & -0.07 & 0.09 & -0.01 & -0.31 & -0.01 & 0.20 & 0.02 \\
\hline Age & -0.69 & -0.17 & $-0.86^{*}$ & -0.21 & $-0.84^{*}$ & -0.21 & $-0.88^{*}$ & -0.21 \\
\hline Negative affect & $0.70^{*}$ & 0.57 & $0.44^{*}$ & 0.35 & $0.42^{*}$ & 0.35 & $0.44^{*}$ & 0.36 \\
\hline ERI ratio & & & $14.00^{*}$ & 0.45 & $14.72^{*}$ & 0.45 & $13.68^{*}$ & 0.44 \\
\hline $\mathrm{OC}$ & & & & & -0.01 & -0.02 & 0.16 & 0.03 \\
\hline ERI ratio $\mathrm{x}$ OC & & & & & & & -0.45 & -0.02 \\
\hline $\mathrm{R}^{2}$ & \multicolumn{2}{|c|}{0.43} & \multicolumn{2}{|c|}{0.58} & \multicolumn{2}{|c|}{0.58} & \multicolumn{2}{|c|}{0.58} \\
\hline$\Delta \mathrm{R}^{2}$ & \multicolumn{2}{|c|}{0.43} & \multicolumn{2}{|c|}{0.16} & \multicolumn{2}{|c|}{0.00} & \multicolumn{2}{|c|}{0.00} \\
\hline$\Delta \mathrm{F}$ & \multicolumn{2}{|c|}{$10.71^{*}$} & \multicolumn{2}{|c|}{$26.53^{*}$} & \multicolumn{2}{|c|}{0.05} & \multicolumn{2}{|c|}{0.07} \\
\hline
\end{tabular}

Table 8. Significant predictors of emotional exhaustion, cynicism, and inefficacy $(\mathrm{N}=79)$

\begin{tabular}{|c|c|c|c|c|c|c|c|}
\hline $\begin{array}{l}\text { Outcome } \\
\text { variable }\end{array}$ & Step & $\begin{array}{l}\text { Significant } \\
\text { predictors }\end{array}$ & B & $\beta$ & $\mathrm{R}^{2}$ & $\Delta \mathrm{R}^{2}$ & $\Delta \mathrm{F}$ \\
\hline \multirow{7}{*}{$\begin{array}{l}\text { Emotional } \\
\text { exhaustion }\end{array}$} & 1 & Negative affect & 0.25 & 0.51 & 0.33 & 0.33 & $7.02^{*}$ \\
\hline & 2 & Negative affect & 0.18 & 0.35 & 0.41 & 0.08 & $9.92^{*}$ \\
\hline & & ERI ratio & 4.09 & 0.33 & & & \\
\hline & 3 & Age & -0.38 & -0.23 & 0.45 & 0.04 & $5.47^{*}$ \\
\hline & & Negative affect & 0.14 & 0.28 & & & \\
\hline & & ERI ratio & 3.65 & 0.29 & & & \\
\hline & & $\mathrm{OC}$ & 0.54 & 0.23 & & & \\
\hline \multirow[t]{3}{*}{ Cynicism } & 1 & Negative affect & 0.27 & 0.50 & 0.33 & 0.33 & $7.08^{*}$ \\
\hline & 2 & Negative affect & 0.20 & 0.37 & 0.39 & 0.06 & $6.91^{*}$ \\
\hline & & ERI ratio & 3.78 & 0.28 & & & \\
\hline \multirow[t]{5}{*}{ Inefficacy } & 1 & Negative affect & 0.18 & 0.32 & 0.19 & 0.19 & $3.44^{*}$ \\
\hline & 2 & Age & -0.45 & -0.24 & 0.34 & 0.15 & 16.28 \\
\hline & & ERI ratio & 6.12 & 0.44 & & & \\
\hline & 3 & ERI ratio & 6.68 & 0.48 & 0.40 & 0.06 & $6.48^{*}$ \\
\hline & & $\mathrm{OC}$ & -0.68 & -0.26 & & & \\
\hline
\end{tabular}

\section{Discussion}

This pilot study analyzed the engagement and burnout of medical students using the ERI model. The ERI ratio was negatively associated with engagement, but $\mathrm{OC}$ was positively associated with engagement (hypotheses 1 and 2 were supported). We did not find an interaction of the ERI ratio and OC for engagement (hypothesis 3 was rejected). The ERI ratio had positive relationship with burnout (hypothesis 4 was supported). OC and the interaction did not significantly explain burnout (hypotheses 5 and 6 were rejected). In addition, affiliation (medical graduate school), lower age, and more negative affect was related to increase in burnout.

The results of this study support the following conclusions. First, the ERI ratio is a useful factor in accounting for the burnout and engagement of medical students in academic settings. Several previous studies (Bakker et al., 2000; Feuerhahn et al., 2012; Kim et al., 2017; Lau, 2008; Lee et al., 2012; Preckel et al., 2007) have confirmed that burnout in workers and adolescents is caused by an imbalance between effort and reward. Positive workplace indicators, such as work engagement or job performance, are also explained by the ERI model 
(Feuerhahn et al., 2012; Inoue et al., 2013; Inoue et al., 2014; Wang et al., 2017). However, positive indicators in school settings had not previously been verified by the ERI model. This study revealed that academic engagement, a positive indicator in school settings, is explained by the ERI model.

Given the small sample size, it is difficult to interpret the results of our study definitively. However, the results for ERI ratio imply that interventions by medical schools to balance effort and reward may reduce burnout and lead to engagement in medical students. A heavy study load (effort) can be decreased by controlling the quantity of education. Medical education is taught by experts in a myriad of fields, and new medical knowledge is increasing exponentially in each field. Therefore, medical education institutions and faculty can regularly monitor and control the amount of education that is taught to students in their curriculum. An optimal balance between effort and reward can be established by increasing reward. The participants in our study became increasingly burned out from the first to the third year (Table 4). Specifically, cynicism showed an upward trend until the third year. Of the two components of the ERI ratio, reward had a significant negative correlation with both burnout $(\mathrm{r}=-0.66)$ and cynicism $(\mathrm{r}=-0.55)$ in our study. Traditionally, interventions to increase rewards in the workplace have consisted of providing monetary rewards (Tsutsumi \& Kawakami, 2004; Wang et al., 2017) building self-esteem (Bakker et al., 2000; Feuerhahn et al., 2012; Tsutsumi \& Kawakami, 2004; Wang et al., 2017), and providing career development opportunities (Tsutsumi \& Kawakami, 2004). Among these methods, medical schools can focus on improving the self-esteem of medical students. In our study, self-esteem items in the reward subscale showed a relatively strong correlation with engagement and burnout (from 0.42 to 0.50 ). Student guidance systems in medical schools can be optimized based on these results. Professors in medical schools regularly meet with students to provide help and advice to them. Supervisors can identify academic stress using the ERI ratio of individual students (Lee et al., 2012) and play a leading role in building the self-esteem of those who do not receive corresponding rewards for their academic endeavors. It will be helpful to develop coaching leadership skills among supervisors so they can better listen to students, provide emotional support, and give adequate feedback on academic performance (Bakker et al., 2000; Tsutsumi \& Kawakami, 2004). A social environment that recognizes and respects medical students' academic efforts is necessary. This environment can be extended to relationships with fellow students, senior mentors, and school counselors.

Second, OC was not significantly related to burnout in medical students, but it was positively related to engagement. This finding for burnout differs from previous studies (Bakker et al., 2000; Lau, 2008; Preckel et al., 2007; Rasmussen et al., 2016) reporting that OC increased burnout in employees. Our result may be explained by the different relationships between $\mathrm{OC}$ and the individual sub-dimensions of burnout. Regression analyses of the sub-dimensions (Table 8) showed that $\mathrm{OC}$ was positively associated with emotional exhaustion, but it was negatively associated with inefficacy. From previous findings in academic settings (Fukuda et al., 2010; Laftman et al., 2014), it can be concluded that student OC has different impacts on general health, depending on characteristics of the student population, such as gender and level of schooling. As for engagement, our results are consistent with previous results based on workplace settings (Kinnunen et al., 2008; Wang et al., 2017). The finding that $\mathrm{OC}$ was positively related to engagement rather than burnout may be explained by the unique characteristics of medical students. Medical students are likely to be high achievers, maintaining their academic achievements through high school (Abdulghani et al., 2014; Ryue \& Lee, 2012). Even when over-committed, their inherent pattern of academic motivation (Kusurkar et al., 2013) may allow them to vigorously and industriously manage a heavy study load (Eley, Leung, Hong, Cloninger, \& Cloninger, 2016). Nevertheless, previous research (Wang et al., 2017) suggests that supervisors and school counselors should observe and manage over-committed students, lest negative health problems be caused by OC.

Third, the interaction between ERI ratio and OC did not significantly explain engagement or burnout in medical students. This result for burnout contrasts with previous studies (Bakker et al., 2000; de Jonge et al., 2000; Feuerhahn et al., 2012; Lau, 2008) reporting that OC worsens the detrimental effect of ERI ratio on workplace burnout. Instead, our finding is consistent with studies (Preckel et al., 2007; Rasmussen et al., 2016) reporting that OC does not significantly moderate the relationship of ERI and burnout. Although there was no interaction effect on academic engagement in this study, the interaction effect on absorption (Figure 1) was similar to a previous research (Kinnunen et al., 2008). In high-ERI ratio conditions, the absorption of over-committed medical students did not decrease sharply (much like the absorption of over-committed managers did not drop sharply), but slightly increased. This may be due to the conscientiousness (Eley et al., 2016) and sense of responsibility (Pawelczyk, Pawelczyk, \& Rabe-Jablonska, 2012) of medical students.

Last, affiliation, age, and negative affect were found to be related to burnout. Students at the college of medicine may experience lower levels of burnout than medical graduate students because of the shorter cumulative duration of education. In Republic of Korea, students in the college of medicine usually enter medical school after graduating from high school. In contrast, medical graduate students begin their medical studies after completing a separate four-year major. Therefore, it is likely that medical graduate students are more vulnerable to burnout. In this study, burnout decreased with age. This result for age is consistent with a previous finding 
(Chun, 2014) that Korean medical students under 23 years of age have significantly higher burnout than older medical students. Negative affect was also found to have significant relationship with burnout in our study. Symptoms commonly found in medical students are depression, anxiety, and stress (Fawzy \& Hamed, 2017; Shi, Liu, Wang, \& Wang, 2016). These symptoms are generally associated with higher negative affect (Watson et al., 1988). Medical students who are depressed or anxious due to academic stress are much more likely to feel negative affect, causing fatigue and a cynical attitude toward their studies.

\section{Conclusion}

This pilot study was designed to improve engagement and reduce burnout in medical students. Medical students have high academic motivation, but they are at risk of burnout because of academic stress. This work has demonstrated that medical students' engagement (positive indicator) and burnout (negative indicator) can be explained by imbalance of effort-reward and over-commitment. We hope that our research will serve as a base for future studies on the ERI model and psychological well-being in medical students.

\section{Limitation of the Study}

Our work clearly has some limitations. First, sample size is small. Because we conduct surveys at the end of each class and course, students could have been reluctant to answer another questionnaire. This may have lowered the participation rate in our study. Given the small sample size, caution must be taken when interpreting the findings. It is proposed that predictive power of the ERI ratio and OC for engagement and burnout is confirmed in future studies. Another limitation is that unlike previous studies (Casuso-Holgado et al., 2013; Gómez et al., 2015; Salanova et al., 2009), the present study did not find an association between engagement and academic achievement. Although engagement and burnout are meaningful indicators of academic well-being, further research can explore the relationship between the ERI model and psychological factors related to medical student academic performance.

\section{References}

Abdulghani, H. M., Al-Drees, A. A., Khalil, M. S., Ahmad, F., Ponnamperuma, G. G., \& Amin, Z. (2014). What factors determine academic achievement in high achieving undergraduate medical students? A qualitative study. Medical Teacher, 36(Suppl 1), S43-S48. http://dx.doi.org/10.3109/0142159X.2014.886011

Aiken, L. S., \& West, S. G. (1991). Multiple regression: Testing and interpreting interactions. Newbury Park, CA: Sage.

Bakker, A. B., Killmer, C. H., Siegrist, J., \& Schaufeli, W. B. (2000). Effort \pm reward imbalance and burnout among nurses. Journal of Advanced Nursing, 31(4), 884-891.

Casuso-Holgado, M. J., Cuesta-Vargas, A. I., Moreno-Morales, N., Labajos-Manzanares, M. T., Barón-López, F. J., \& Vega-Cuesta, M. (2013). The association between academic engagement and achievement in health sciences students. BMC Medical Education, 13(1), 33-39.

Choo, H. T., \& Sohn, W. S. (2012). A validating academic engagement as a multidimensional construct for Korean college students: academic motivation, engagement, and satisfaction. Korean Journal of School Psychology, 12, 485-503.

Chun, K. H. (2014). Relationship between academic burnout of medical and graduate students and related variables. Korean Medical Education Review, 16(2), 77-87.

Chunming, W. M., Harrison, R., MacIntyre, R., Travaglia, J., \& Balasooriya, C. (2017). Burnout in medical students: a systematic review of experiences in Chinese medical schools. BMC Medical Education, 17(1), 217-227. http://dx.doi.org/10.1186/s12909-017-1064-3

de Jonge, J., Bosma, H., Peter, R., \& Siegrist, J. (2000). Job strain, effort-reward imbalance and employee wellbeing: a large-scale cross-sectional study. Social Science \& Medicine, 50(9), 1317-1327.

Demerouti, E., Mostert, K., \& Bakker, A. B. (2010). Burnout and work engagement: a thorough investigation of the independency of both constructs. Journal of Occupational Health Psychology, 15(3), 209-222.

Eley, D. S., Leung, J., Hong, B. A., Cloninger, K. M., \& Cloninger, C. R. (2016). Identifying the dominant personality pofiles in medical students: implications for their well-being and resilience. Plos One, 11(8), e0160028. http://dx.doi.org/10.1371/journal.pone.0160028

Enns, M. W., Cox, B. J., Sareen, J., \& Freeman, P. (2001). Adaptive and maladaptive perfectionism in medical students: a longitudinal investigation. Medical Education, 35(11), 1034-1042.

Fawzy, M., \& Hamed, S. A. (2017). Prevalence of psychological stress, depression and anxiety among medical students in Egypt. Psychiatry Research, 255, 186-194. http://dx.doi.org/10.1016/j.psychres.2017.05.027

Feldt, T., Huhtala, M., Kinnunen, U., Hyvönen, K., Mäkikangas, A., \& Sonnentag, S. (2013). Long-term patterns 
of effort-reward imbalance and over-commitment: investigating occupational well-being and recovery experiences as outcomes. Work \& Stress, 27(1), 64-87. http://dx.doi.org/10.1080/02678373.2013.765670

Feuerhahn, N., Kühnel, J., \& Kudielka, B. M. (2012). Interaction effects of effort-reward imbalance and overcommitment on emotional exhaustion and job performance. International Journal of Stress Management, 19(2), 105-131. http://dx.doi.org/10.1037/a0028338

Fukuda, S., Yamano, E., Joudoi, T., Mizuno, K., Tanaka, M., Kawatani, J., . . . Watanabe, Y. (2010). Effort-reward imbalance for learning is associated with fatigue in school children. Behavioral Medicine, 36(2), 53-62. http://dx.doi.org/10.1080/08964281003774919

Gómez, P., Pérez, C., Parra, P., Ortiz, L., Matus, O., Mccoll, P., . . Meyer, A. (2015). Academic achievement, engagement and burnout among first year medical students. Revista Medica de Chile, 143, 930-937.

Hahn, H., Kropp, P., Kirschstein, T., Rucker, G., \& Muller-Hilke, B. (2017). Test anxiety in medical school is unrelated to academic performance but correlates with an effort/reward imbalance. Plos One, 12(2), e0171220. http://dx.doi.org/10.1371/journal.pone.0171220

Inoue, A., Kawakami, N., Tsuno, K., Shimazu, A., Tomioka, K., \& Nakanishi, M. (2013). Job demands, job resources, and work engagement of Japanese employees: a prospective cohort study. International Archives of Occupational and Environmental Health, 86(4), 441-449. http://dx.doi.org/10.1007/s00420-012-0777-1

Inoue, A., Kawakami, N., Tsutsumi, A., Shimazu, A., Miyaki, K., Takahashi, M., . . . Totsuzaki, T. (2014). Association of job demands with work engagement of Japanese employees: comparison of challenges with hindrances (J-HOPE). Plos One, 9(3), e91583. http://dx.doi.org/10.1371/journal.pone.0091583

Jafari, N., Loghmani, A., \& Montazeri, A. (2012). Mental health of medical students in different levels of training. International Journal of Preventive Medicine, 3(Supp11), S107-S112.

Kim, B. Y., Kim, E., \& Lee, S. M. (2017). Examining longitudinal relationship among effort reward imbalance, coping strategies and academic burnout in Korean middle school students. School Psychology International, $38,1-19$.

Kinnunen, U., Feldt, T., \& Makikangas, A. (2008). Testing the effort-reward imbalance model among Finnish managers: the role of perceived organizational support. Journal of Occupational Health Psychology, 13(2), 114-127. http://dx.doi.org/10.1037/1076-8998.13.2.114

Kroska, E. B., Calarge, C., O’Hara, M. W., Deumic, E., \& Dindo, L. (2017). Burnout and depression in medical students: Relations with avoidance and disengagement. Journal of Contextual Behavioral Science, 6(4), 404-408.

Kusurkar, R. A., Croiset, G., Galindo-Garré, F., \& Ten Cate, O. (2013). Motivational profiles of medical students: association with study effort, academic performance and exhaustion. BMC Medical Education, 13, 87-94.

Kusurkar, R. A., Ten Cate, T. J., van Asperen, M., \& Croiset, G. (2011). Motivation as an independent and a dependent variable in medical education: a review of the literature. Medical Teacher, 33(5), e242-e262. http://dx.doi.org/10.3109/0142159X.2011.558539

Laftman, S. B., Modin, B., Ostberg, V., Hoven, H., \& Plenty, S. (2014). Effort-reward imbalance in the school setting: associations with somatic pain and self-rated health. Scandinavian Journal of Public Health, 43(2), 123-129. http://dx.doi.org/10.1177/1403494814561818

Lau, B. (2008). Effort-reward imbalance and overcommitment in employees in a Norwegian municipality: a cross sectional study. Journal of Occupational Medicine and Toxicology, 3, 9. http://dx.doi.org/10.1186/1745-6673-3-9

Lee, H. H., Kim, E. J., \& Lee, M. K. (2003). A validation study of Korea positive and negative affect schedule: the PANAS Scales. Korean Journal of Clinical Psychology, 22(4), 935-946.

Lee, J., Puig, A., \& Lee, S. M. (2012). The effect of the demand control and effort reward imbalance models on the academic burnout of Korean adolescents. Asia Pacific Journal of Education, 32(1), 113-123. http://dx.doi.org/10.1080/02188791.2012.655373

Lee, S. H., \& Lee, D. Y. (2013). Validation of the MBI-SS scales - based on medical school students. Asian Journal of Education, 14(2), 165-187.

Lee, Y. B., Lee, S. M., \& Lee, J. (2009). Development of Korean academic burnout scale. The Korean Educational Review, 15(3), 59-78.

Maslach, C., \& Leiter, M. P. (2017). New insights into burnout and health care: strategies for improving civility $\begin{array}{llll}\text { and alleviating } \quad \text { burnout. } & \text { Medical } & \text { 160-163. }\end{array}$ http://dx.doi.org/10.1080/0142159X.2016.1248918 
Pawelczyk, A., Pawelczyk, T., \& Rabe-Jablonska, J. (2012). Medical students hierarchy of values and sense of responsibility. Teaching and Learning in Medicine, 24(3), 211-214. http://dx.doi.org/10.1080/10401334.2012.692264

Preckel, D., Meinel, M., Kudielka, B. M., Haug, H. J., \& Fischer, J. E. (2007). Effort-reward-imbalance, overcommitment and self-reported health: is it the interaction that matters?. Journal of Occupational and Organizational Psychology, 80(1), 91-107. http://dx.doi.org/10.1348/096317905x80183

Rasmussen, V., Turnell, A., Butow, P., Juraskova, I., Kirsten, L., Wiener, L., . . Grassi, L. (2016). Burnout among psychosocial oncologists: an application and extension of the effort-reward imbalance model. Psychooncology, 25(2), 194-202. http://dx.doi.org/10.1002/pon.3902

Ryue, S. H., \& Lee, H. B. (2012). Korean medical students' cognitive, emotional, and social characteristics. Korean Journal of Medical Education, 24(2), 103-115. http://dx.doi.org/10.3946/kjme.2012.24.2.103

Salanova, M., Schaufeli, W., Martínez, I., \& Breso, E. (2009). How obstacles and facilitators predict academic performance: the mediating role of study burnout and engagement. Anxiety, stress \& coping, 23(1), 53-70.

Schaufeli, W. B., Martinez, I. M., Pinto, A. M., Salanova, M., \& Baker, A. B. (2002). Burnout and engagement in university students: a cross-national study. Journal of Cross-Cultural Psychology, 33(5), 464-481.

Schaufeli, W. B., Salanova, M., Gonzalez-roma, V., \& Bakker, A. B. (2002). The measurement of engagement and burnout: a two sample confirmatory factor analytic approach. Journal of Happiness Studies, 3, 71-92.

Shankar, P. R., Balasubramanium, R., Ramireddy, R., Diamante, P., Barton, B., \& Dwivedi, N. R. (2014). Stress and coping strategies among premedical and undergraduate basic science medical students in a Caribbean medical school. Education in Medicine Journal, 6(4), 48-56.

Shi, M., Liu, L., Wang, Z. Y., \& Wang, L. (2016). Prevalence of depressive symptoms and its correlations with positive psychological variables among Chinese medical students: an exploratory cross-sectional study. BMC Psychiatry, 16, 3. http://dx.doi.org/10.1186/s12888-016-0710-3

Siegrist, J. (1996). Adverse health effects of high-effort/low-reward conditions. Journal of Occupational Health Psychology, 1(1), 27-41.

Siegrist, J., Starke, D., Chandola, T., Godin, I., Marmot, M., Niedhammer, I., \& Peter, R. (2004). The measurement of effort-reward imbalance at work: European comparisons. Social Science and Medicine, 58(8), 1483-1499. http://dx.doi.org/10.1016/s0277-9536(03)00351-4

Siegrist, J., Wege, N., Puhlhofer, F., \& Wahrendorf, M. (2009). A short generic measure of work stress in the era of globalization: effort-reward imbalance. International Archives of Occupational and Environmental Health, 82(8), 1005-1013. http://dx.doi.org/10.1007/s00420-008-0384-3

Tsutsumi, A., \& Kawakami, N. (2004). A review of empirical studies on the model of effort-reward imbalance at work: reducing occupational stress by implementing a new theory. Social Science \& Medicine, 59(11), 2335-2359. http://dx.doi.org/10.1016/j.socscimed.2004.03.030

van Vegchel, N., de Jonge, J., Bosma, H., \& Schaufeli, W. (2005). Reviewing the effort-reward imbalance model: drawing up the balance of 45 empirical studies. Social Science \& Medicine, 60(5), 1117-1131. http://dx.doi.org/10.1016/j.socscimed.2004.06.043

Wang, X., Liu, L., Zou, F., Hao, J., \& Wu, H. (2017). Associations of occupational stressors, perceived organizational support, and psychological capital with work engagement among Chinese female nurses. BioMed Research International, 2017, 5284628. http://dx.doi.org/10.1155/2017/5284628

Watson, D., Clark, L. A., \& Tellegen, A. (1988). Development and validation of brief measures of positive and negative affect: The PANAS scales. Journal of Personality and Social Psychology, 54(6), 1063-1070.

Wege, N., Li, J., Muth, T., Angerer, P., \& Siegrist, J. (2017). Student ERI: psychometric properties of a new brief measure of effort-reward imbalance among university students. Journal of Psychosomatic Research, 94, 64-67. http://dx.doi.org/10.1016/j.jpsychores.2017.01.008

\section{Copyrights}

Copyright for this article is retained by the author(s), with first publication rights granted to the journal.

This is an open-access article distributed under the terms and conditions of the Creative Commons Attribution license (http://creativecommons.org/licenses/by/4.0/). 